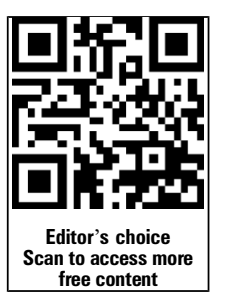

free content
foe

- Additional material is published online. To view please visit the journal (http:// dx.doi.org/10.1136/sextrans2015-052073)

1 Department of General Practice, Division of Clinical Methods and Public Health, Academic Medical Center, Amsterdam, The Netherlands ${ }^{2}$ Department of Internal Medicine, Division of Infectious Diseases, Academic Medical Center, Amsterdam, The Netherlands

${ }^{3}$ STI AIDS Netherlands (Soa Aids Nederland) Amsterdam, The Netherlands ${ }^{4}$ Epidemiology \& Surveillance Unit, Centre for Infectious Disease Control, National Institute of Public Health and the Environment (RIVM), Bilthoven, The Netherlands

Correspondence to Ivo K Joore, Department of General Practice, Division of Clinical Methods and Public Health, Academic Medical Center, Meibergdreef 9, Amsterdam $1100 \mathrm{DE}$

The Netherlands;

i.k.joore@amc.uva.nl

Received 4 March 2015 Revised 29 May 2015 Accepted 13 June 2015 Published Online First 30 June 2015

\section{SLinked}

- http://dx.doi.org/10.1136/ sextrans-2015-052229

\section{CrossMark}

To cite: Joore IK, Arts DL, Kruijer MJP, et al. Sex

Transm Infect 2015;91:467472.

\title{
HIV indicator condition-guided testing to reduce the number of undiagnosed patients and prevent late presentation in a high-prevalence area: a case-control study in primary care
}

\author{
Ivo K Joore, ${ }^{1}$ Derk L Arts, ${ }^{1}$ Marjan JP Kruijer, ${ }^{1}$ Eric P Moll van Charante, ${ }^{1}$ \\ Suzanne E Geerlings, ${ }^{2}$ Jan M Prins, ${ }^{2}$ Jan EAM van Bergen ${ }^{1,3,4}$
}

\begin{abstract}
Objectives Recent guidelines advocate accelerated provider-initiated HIV testing by general practitioners (GPs). We aimed to identify the number of patient consultations in six general practices in the South-East of Amsterdam, and the incidence of HIV indicator conditions reported in their medical files prior to diagnosis.
\end{abstract}

Methods A cross-sectional search in an electronic general practice database. We used a case-control design to identify those conditions most associated with an HIVpositive status.

Results We included 102 HIV cases diagnosed from 2002 to 2012, and matched them with 299 controls. In the year prior to HIV diagnosis, $61.8 \%$ of cases visited their GP at least once, compared with $38.8 \%$ of controls. In the 5 years prior to HIV diagnosis, $58.8 \%$ of HIV cases had exhibited an HIV indicator condition, compared with $7.4 \%$ of controls. The most common HIV-related conditions were syphilis and gonorrhoea. The most common HIV-related symptoms were weight loss, lymphadenopathy and peripheral neuropathy. During this period, average HIV prevalence among people aged $15-59$ years increased from $0.4 \%$ to $0.9 \%$.

Conclusions This study revealed many opportunities for HIV indicator condition-guided testing in primary care. As yet, however, HIV indicator conditions are not exploited as triggers for early HIV testing.

\section{INTRODUCTION}

An estimated 25000 individuals in the Netherlands are living with HIV, a quarter of whom are estimated to be undiagnosed. ${ }^{1}$ In 2013, 1100 patients with HIV were diagnosed. Of these, $43 \%$ presented late for care, with AIDS or with a CD4 count $<350$ cells $/ \mathrm{mm}^{3}{ }^{1}$ Late diagnosis is associated with higher morbidity and mortality. ${ }^{2}{ }^{3}$ In the Netherlands, the HIV epidemic is concentrated among men who have sex with men and individuals from HIV endemic countries. ${ }^{1}$

In recent years, 'Treatment as Prevention' has become an important strategy in fighting the HIV epidemic. ${ }^{4}$ The early detection and treatment of HIV infection provide benefits for the health of the individual and that of the public at large. ${ }^{56}$

As the primary point of access to healthcare, general practitioners (GPs) have a pivotal role. They could play an important part in providerinitiated HIV testing for early case-finding. ${ }^{7-10}$ For many years, national guidelines for GPs have recommended HIV testing strategies that target populations at higher risk of HIV. ${ }^{11}$ However, this 'high-risk' approach has certain intrinsic limitations, which restrict its implementation in primary healthcare. ${ }^{7}$ There is a need for alternative and additional provider-initiated HIV testing strategies. Details of two new, targeted HIV testing strategies have recently been published. ${ }^{10}{ }^{12-14}$ With regard to the first of these, the European Centre for Disease Prevention and Control (ECDC) recommends offering an HIV test to individuals with HIV indicator conditions defined as: (1) conditions which are AIDS-defining among people living with HIV, (2) conditions associated with an undiagnosed HIV infection with a prevalence of $>0.1 \%$ and (3) conditions in which missing a diagnosis of HIV infection may have significant adverse implications for the individual's clinical management. ${ }^{14}$ With regard to the second new strategy, the National Institute for Health and Care Excellence (NICE) recommends 'routine HIV testing' in primary care settings where HIV prevalence exceeds 2 per 1000 among people aged $15-59$ years. ${ }^{12} 13$ 'Routine HIV testing' involves offering an HIV test to new patients during registration, and to anyone undergoing a laboratory blood test, regardless of the indication. A qualitative UK study reported that the public finds the offer of testing for HIV upon GP registration acceptable in high-prevalence areas. ${ }^{15}$ The advantage of the newly proposed HIV testing strategies is that they avoid the barriers that GPs usually encounter when taking a sexual history or when making a risk assessment. This could help to normalise and destigmatise the use of the HIV test.

In order to estimate the potential usefulness of these strategies, we obtained data on the number of patient consultations and on the incidence of HIV indicator conditions reported in their medical files 5 years prior to diagnosis. We also determined HIV prevalence rates from 2002 to 2012, in six general practices in the South-Eastern suburbs of Amsterdam; a case-control study using routinely collected general-practice data.

\section{METHODS}

\section{Data source}

The 'HAG-net-AMC' general practice database contains the electronic patient records of 
approximately 46000 patients. These individuals are registered in six general practices located in the South-East of Amsterdam, a culturally diverse and socioeconomically deprived area. The database contains information on laboratory results, medical diagnoses, prescriptions and treatments. The standard information recorded in patients' medical files does not include details of sexual orientation, ethnicity and socioeconomic status.

\section{Study design}

A search was performed for patients with HIV infection who were diagnosed between July 2002 and July 2012 using International Classification of Primary Care (ICPC) code B90 (HIV-infection). ${ }^{16}$ We used a case-control design to evaluate the number of patient consultations and HIV indicator conditions for each patient prior to HIV diagnosis. We matched cases to controls that were considered to be HIV free. Inclusion criteria for cases were: newly diagnosed HIV infection in the study period, age $\geq 18$ years and more than 1 year of information available in the medical file prior to HIV diagnosis. Controls (ratio 1:3) were matched for age, sex, practice, year the cases received their diagnosis and years of information in the medical file available prior to diagnosis.

\section{Patient consultations prior to HIV diagnosis}

We obtained details from the database of the number of times that each patient had consulted his/her GP. This was supplemented by data on the number of laboratory blood tests for patients 1 year prior to HIV diagnosis plus details of the number of new patients registering with the general practice.

\section{HIV indicator conditions prior to HIV diagnosis}

We searched the data on patient consultations prior to HIV diagnosis for preselected HIV indicator conditions based on the ECDC guideline (table 1). ${ }^{14}$ We selected those HIV indicator conditions that GPs in the Netherlands diagnose themselves. As many HIV indicator conditions are not ICPC coded, we also searched the consultation records' open evaluation text fields (where most of the important symptoms and clinical diagnosis details are reported). Any conditions that are unlikely to be diagnosed by a GP (such as visceral leishmaniasis, GuillainBarré syndrome, Kaposi's sarcoma and pneumocystis carinii pneumonia) were excluded. No neoplasms were included, as these conditions are also diagnosed in secondary or tertiary hospital settings. Pregnancy was excluded, as all pregnant women in the Netherlands are routinely tested for HIV with an opt-out approach. ${ }^{1}$ A mononucleosis-like illness was considered if at least two of the following symptoms were present in the medical record's open evaluation text fields: fever, swollen lymph glands and rash with or without pharyngitis, muscle aches and feeling sick. ${ }^{17}$ If there were symptoms in the evaluation text fields that might indicate a mononucleosis-like illness, we also searched the other text fields for validating evidence. We used the same strategy for the controls.

\section{Statistical analyses}

Exact logistic regression was used to identify preselected HIV indicator conditions associated with the occurrence of HIV. This type of regression was used because the sample size was too small to accommodate all of the selected variables, and some of the cells had no observations at all. We included 26 HIV indicator conditions as variables, as well as the total number of HIV indicator conditions and the total number of sexually transmitted infections (STIs) prior to HIV diagnosis. ORs were calculated with 95\% CIs using STATA statistical analysis software
Table 1 Operational definitions of HIV indicator conditions

\begin{tabular}{|c|c|}
\hline $\begin{array}{l}\text { ECDC guideline for HIV } \\
\text { indicator conditions }{ }^{14}\end{array}$ & Operational definition \\
\hline Sexually transmitted infections & $\begin{array}{l}\text { Chlamydia, gonorrhoea, syphilis, hepatitis B, } \\
\text { genital herpes, lymphogranuloma venereum, } \\
\text { Condyloma acuminata and trichomoniasis }\end{array}$ \\
\hline Chlamydia & Chlamydia \\
\hline Gonorrhoea & Gonorrhoea \\
\hline Syphilis & Syphilis \\
\hline Hepatitis B & Hepatitis B \\
\hline Genital herpes & Genital herpes \\
\hline Lymphogranuloma venereum & Lymphogranuloma venereum \\
\hline Condyloma acuminata & Condyloma acuminata \\
\hline Trichomoniasis & Trichomoniasis \\
\hline Acute or chronic hepatitis A & Hepatitis A \\
\hline Acute or chronic hepatitis C & Hepatitis C \\
\hline Herpes zoster & Herpes zoster \\
\hline Severe or atypical psoriasis & Psoriasis \\
\hline $\begin{array}{l}\text { Seborrhoeic dermatitis/ } \\
\text { exanthema }\end{array}$ & Seborrhoeic dermatitis \\
\hline Cervical dysplasia & Cervical dysplasia \\
\hline Community-acquired pneumonia & Pneumonia \\
\hline Unexplained oral candidiasis & Oral candidiasis \\
\hline Mononeuritis & Mononeuritis \\
\hline Peripheral neuropathy & Peripheral neuropathy \\
\hline Mononucleosis-like illness & $\begin{array}{l}\text { Mononucleosis-like illness is defined as illness } \\
\text { with at least two of these symptoms: rash, } \\
\text { fever and swollen lymph glands, with or } \\
\text { without muscle aches, sore throat and feeling } \\
\text { sick }\end{array}$ \\
\hline Unexplained fever & Fever \\
\hline Unexplained weight loss & Weight loss \\
\hline Unexplained lymphadenopathy & Lymphadenopathy \\
\hline Unexplained chronic diarrhoea & Diarrhoea \\
\hline $\begin{array}{l}\text { Unexplained leucocytopenia } \\
\text { lasting }>4 \text { weeks }\end{array}$ & Leucocytopenia \\
\hline $\begin{array}{l}\text { Unexplained thrombocytopenia } \\
\text { lasting }>4 \text { weeks }\end{array}$ & Thrombocytopenia \\
\hline $\begin{array}{l}\text { Unexplained chronic renal } \\
\text { impairment }\end{array}$ & Chronic renal impairment \\
\hline
\end{tabular}

(V.13.1). The numbers of patient consultations were analysed for significance using $\chi^{2}$ statistics. $\mathrm{p}$ Values $\leq 0.05$ (two-tailed) were considered to be significant.

\section{RESULTS}

\section{Characteristics of cases and controls}

A total of 452 cases were found by searching for B90 (the ICPC code mentioned above). We excluded 350 cases for the following reasons: one case did not have HIV, 291 cases were diagnosed before 1 July 2002, 10 cases involved individuals below the age of 18 and 48 cases had medical files that predated HIV diagnosis by no more than 1 year. Data from 102 HIV-positive cases were matched to 299 controls considered to be free of HIV. The majority of cases $(72.5 \%)$ were male, with a mean age of 44.5 (SD 9.5). The median period covered by the available medical data was 5.0 years for both groups.

\section{Patient consultations in general practices}

The majority of cases (61.8\%) visited their GP at least once (median 3), compared with $38.8 \%$ of the controls (median 2) 
Table 2 Patient consultations in six general practices in the South-East of Amsterdam

\begin{tabular}{|c|c|c|c|c|c|}
\hline & \multicolumn{2}{|c|}{ Cases } & \multicolumn{2}{|c|}{ Controls } & \multirow[b]{2}{*}{ p Value } \\
\hline & $\mathrm{n}$ & $\%$ & $\mathrm{n}$ & $\%$ & \\
\hline & 102 & & 299 & & \\
\hline Patient consultations* & 63 & 61.8 & 116 & 38.8 & $<0.01$ \\
\hline One face-to-face consultation & 12 & 11.8 & 41 & 13.7 & \\
\hline Two face-to-face consultations & 7 & 6.9 & 24 & 8.0 & \\
\hline $\begin{array}{l}\text { Three or more face-to-face } \\
\text { consultations }\end{array}$ & 44 & 43.1 & 51 & 17.1 & \\
\hline $\begin{array}{l}\text { Number of face-to-face } \\
\text { consultations } \\
\text { (median, IQR) }\end{array}$ & 3 & $2-3$ & 2 & $1-3$ & \\
\hline Laboratory blood tests $\dagger$ & 40 & 39.2 & 56 & 18.7 & $<0.01$ \\
\hline One blood test & 28 & 27.5 & 39 & 13.0 & \\
\hline Two blood tests & 7 & 6.9 & 4 & 1.3 & \\
\hline Three or more blood tests & 5 & 4.9 & 13 & 4.3 & \\
\hline
\end{tabular}

${ }^{*}$ Number of patient consultations in the year prior to HIV diagnosis.

tNumber of laboratory blood tests registered in the year prior to HIV diagnosis.

(table 2). In 39.2\% of the HIV cases, one or more laboratory blood tests were performed in the year prior to diagnosis, against $18.7 \%$ in the control group. Each year, approximately $\mathrm{n}=2554(5.6 \%)$ patients registered with these general practices, and visited them for the first time.

\section{HIV indicator conditions}

In the 5 years prior to HIV diagnosis, more than half of all HIV cases $(58.8 \%)$ were diagnosed with one or more of the HIV indicator conditions, compared with $7.4 \%$ for controls (table 3 ). The most common HIV-related conditions were syphilis $(n=12)$, chlamydia $(n=11)$, pneumonia $(n=8)$, mononucleosislike illness $(n=8)$ and herpes zoster $(n=7)$. The most common HIV-related symptoms recorded were weight loss $(n=9)$ and lymphadenopathy $(n=7)$.

Several HIV indicator conditions were not observed in the control group. As a result, the $95 \%$ CIs of a number of HIV indicator conditions ranged from OR to infinity $(\infty)$ (table 3 ). The HIV indicator conditions most strongly associated with the occurrence of HIV were weight loss (OR 39.6, 95\% CI 6.2 to $\infty$ ), syphilis (OR 39.3, 95\% CI 5.7 to 1703.9), lymphadenopathy (OR 29.8, 95\% CI 4.4 to $\infty$ ), gonorrhoea (OR 15.9, 95\% CI 2.0 to $\infty$ ) and peripheral neuropathy (OR 15.9, 95\% CI 2.0 to $\infty)$. The number of HIV indicator conditions prior to HIV diagnosis was associated with the occurrence of HIV: one HIV indicator condition OR 11.7 (95\% CI 6.0 to 23.6) and two or more HIV indicator conditions OR 77.5 (95\% CI 18.2 to 700.8). Also, the total number of STIs in the 5 years prior to HIV diagnosis was associated with the occurrence of HIV: one STI OR 14.6 (95\% CI 5.5 to 45.6$)$ and two or more STIs OR 37.9 (95\% CI 5.6 to $\infty$ ).

\section{HIV prevalence rates at six general practices in South-East of Amsterdam}

From 2002 to 2012, average HIV prevalence among people aged $15-59$ years increased from $0.4 \%$ to $0.9 \%$ (figure 1 ), which is well above the average of $0.2 \%$ that represents a highprevalence area, according to the UK's NICE guideline. ${ }^{12} 13$

\section{DISCUSSION}

In the year prior to their diagnosis, most patients with HIV consulted their GP, and more than half of them were diagnosed with an HIV indicator condition in the 5 years preceding the diagnosis, compared with only $7.4 \%$ of the controls. The presence of HIV was mostly associated with symptoms of weight loss, lymphadenopathy and peripheral neuropathy and with the clinical diagnoses of syphilis and gonorrhoea. From 2002 to 2012, in the South-East of Amsterdam, average HIV prevalence among people aged 15-59 years increased from $0.4 \%$ to $0.9 \%$.

A UK study reported that in the year prior to HIV diagnosis, $76.4 \%$ of African patients who were newly diagnosed with HIV had consulted their GP. ${ }^{18}$ A French study reported that $89 \%$ of patients newly diagnosed with HIV had consulted a GP at least once a year. ${ }^{19}$ In our study, $61.8 \%$ of patients in the year prior to HIV diagnosis had consulted their GP compared with $38.8 \%$ of controls. All studies showed that patients frequently visited their GP, indicating that opportunities to diagnose HIV at an earlier point in time had been missed. In our study, the number of consultations prior to HIV diagnosis was higher among cases than among controls. This might be explained by the fact that patients with HIV tend to visit their GP more often, in connection with HIV-related conditions.

The revised national STI guideline for GPs in the Netherlands addresses the importance of offering an HIV test to individuals who display HIV indicator conditions, which is in line with the ECDC guideline. ${ }^{11}{ }^{14}$ A large Italian cohort showed the importance of testing for HIV following the diagnosis of HIV indicator conditions, as this significantly decreases the probability of late HIV diagnosis. ${ }^{20}$ A UK general practice case-control study found that $25.8 \%$ of HIV cases had presented with one or more HIV indicator conditions 1 year prior to receiving a diagnosis of $\mathrm{HIV}^{21}$ In our study, we found that $58.8 \%$ of the HIV cases had HIV indicator conditions in the 5 years prior to HIV diagnosis. The large numbers of local residents who originate from countries where HIV is endemic may well account for the higher percentage of HIV indicator conditions found in our study population in the South-Eastern suburbs of Amsterdam. ${ }^{1} 22$

Mononucleosis-like illness is an important HIV indicator condition because it can indicate acute HIV infection. ${ }^{14}$ In primary healthcare settings, individuals presenting with a mononucleosislike illness should be strongly advised to take an HIV test, as this condition meets the criteria for cost-effectiveness. ${ }^{23} 24$ This illness was observed in our study in $7.8 \%$ of HIV cases in the 5 years prior to diagnosis.

A recent 'landmark' article concluded that epidemics differ in concentration from one country to another, exhibiting different levels of transmission and different risk groups, and changing over time. Its authors recommended a focused public health approach that prioritises high-transmission geographies and populations at higher risk of HIV, while combining the most cost-effective interventions. ${ }^{25}$ The UK NICE guideline also builds on prioritising high-transmission geographies, by recommending more 'routine HIV testing' in highprevalence areas, for example, in newly registered patients and during routine laboratory blood tests. ${ }^{12}$ In the UK, however, the concept of 'routine HIV testing' in highprevalence areas is not well implemented. ${ }^{26} 27$ Our data indicate opportunities for routine testing in this particular area of Amsterdam, which qualifies as a high-prevalence area: in $39.2 \%$ of HIV cases, one or more laboratory blood tests were 
Table 3 Number of HIV indicator conditions in cases and controls

\begin{tabular}{|c|c|c|c|c|c|c|c|c|}
\hline \multirow[b]{3}{*}{$\mathrm{N}$} & \multicolumn{2}{|c|}{ Cases } & \multicolumn{2}{|c|}{ Controls } & \multirow[b]{3}{*}{ OR } & \multirow[b]{3}{*}{$95 \% \mathrm{Cl}$} & & \multirow[b]{3}{*}{$\mathrm{p}$ Value } \\
\hline & \multicolumn{2}{|c|}{102} & \multicolumn{2}{|l|}{299} & & & & \\
\hline & $\mathrm{n}$ & $\%$ & $n$ & $\%$ & & & & \\
\hline Sexually transmitted infections (STIs) & 29 & 28.4 & 6 & 2.0 & & & & \\
\hline \multicolumn{9}{|l|}{ Number of STIs per patient } \\
\hline None & 73 & 71.6 & 293 & 98.0 & & & & \\
\hline One & 22 & 21.6 & 6 & 2.0 & 14.6 & 5.5 & 45.6 & $<0.001$ \\
\hline Two or more & 7 & 6.9 & 0 & 0 & 37.9 & 5.6 & $\infty$ & $<0.001$ \\
\hline Syphilis & 12 & 11.7 & 1 & 0.3 & 39.3 & 5.7 & 1703.9 & $<0.001$ \\
\hline Gonorrhoea & 4 & 3.9 & 0 & 0 & 15.9 & 2.0 & $\infty$ & 0.008 \\
\hline Condyloma acuminata & 4 & 3.9 & 1 & 0.3 & 12.1 & 1.2 & 600.9 & 0.032 \\
\hline Chlamydia & 11 & 10.8 & 3 & 1.0 & 11.8 & 3.0 & 67.5 & $<0.001$ \\
\hline Hepatitis B & 3 & 2.9 & 0 & 0 & 11.5 & 1.2 & $\infty$ & 0.032 \\
\hline Lymphogranuloma venereum & 2 & 2.0 & 0 & 0 & 7.1 & 0.6 & $\infty$ & 0.129 \\
\hline Genital herpes & 1 & 1.0 & 0 & 0 & 2.9 & 0.1 & $\infty$ & 0.509 \\
\hline Trichomoniasis & 0 & 0 & 1 & 0.3 & 2.9 & 0.0 & 114.3 & 1.000 \\
\hline \multicolumn{9}{|l|}{ Clinical diagnosis } \\
\hline Leucocytopenia & 3 & 2.9 & 0 & 0 & 11.5 & 1.2 & $\infty$ & 0.032 \\
\hline Herpes zoster & 7 & 6.9 & 2 & 0.7 & 10.9 & 2.0 & 108.9 & 0.003 \\
\hline Pneumonia & 8 & 7.8 & 3 & 1.0 & 8.3 & 2.0 & 49.8 & 0.002 \\
\hline Oral candidiasis & 2 & 2.0 & 0 & 0 & 7.1 & 0.6 & $\infty$ & 0.129 \\
\hline Mononucleosis-like illness & 8 & 7.8 & 4 & 1.3 & 6.2 & 1.6 & 29.0 & 0.005 \\
\hline Psoriasis & 1 & 1.0 & 0 & 0 & 2.9 & 0.1 & $\infty$ & 0.509 \\
\hline Cervical dysplasia & 1 & 1.0 & 1 & 0.3 & 2.9 & 0.4 & 232.4 & 0.889 \\
\hline Seborrhoeic dermatitis & 1 & 1.0 & 3 & 1.0 & 1.0 & 0.0 & 12.3 & 1.000 \\
\hline Thrombocytopenia & 0 & 0 & 0 & 0 & & & & \\
\hline Chronic renal impairment & 0 & 0 & 0 & 0 & & & & \\
\hline Hepatitis A & 0 & 0 & 0 & 0 & & & & \\
\hline Hepatitis C & 0 & 0 & 0 & 0 & & & & \\
\hline Mononeuritis & 0 & 0 & 0 & 0 & & & & \\
\hline \multicolumn{9}{|l|}{ Symptoms } \\
\hline Weight loss & 9 & 8.8 & 0 & 0 & 39.6 & 6.2 & $\infty$ & $<0.001$ \\
\hline Lymphadenopathy & 7 & 6.9 & 0 & 0 & 29.8 & 4.4 & $\infty$ & $<0.001$ \\
\hline Peripheral neuropathy & 4 & 3.9 & 0 & 0 & 15.9 & 2.0 & $\infty$ & 0.008 \\
\hline Fever & 3 & 2.9 & 2 & 0.7 & 4.5 & 0.5 & 54.3 & 0.214 \\
\hline Diarrhoea & 2 & 2.0 & 3 & 1.0 & 2.0 & 0.2 & 17.4 & 0.753 \\
\hline HIV indicator conditions & 60 & 58.8 & 22 & 7.4 & & & & \\
\hline \multicolumn{9}{|c|}{ Number of HIV indicator conditions per patient } \\
\hline None & 42 & 41.2 & 277 & 92.6 & & & & \\
\hline One & 36 & 35.3 & 20 & 6.7 & 11.7 & 6.0 & 23.6 & $<0.001$ \\
\hline Two or more & 24 & 23.5 & 2 & 0.7 & 77.5 & 18.2 & 700.8 & $<0.001$ \\
\hline
\end{tabular}

performed 1 year prior to diagnosis. In addition, each year, approximately $5.6 \%$ of patients registered with these general practices and visited them for the first time. Greater insight is needed into the barriers or motivators encountered by GPs in implementing these new provider-initiated HIV testing strategies.

Our data have several limitations due to the cross-sectional nature of the study design and due to limitations in the electronic registration system used by the general practices in question. In the control group, $7.4 \%$ of the patients exhibited at least one HIV indicator condition prior to diagnosis. It is possible that some of the controls with HIV indicator conditions were HIV positive as their HIV status was unknown. However, this misclassification would tend to increase rather than decrease the ORs.
Additionally, wide 95\% CI were observed for many indicator conditions due to the low number of HIV indicator conditions. HIV indicator conditions in the evaluation lines could be subject to under-reporting by GPs. However, this would be expected to occur in both groups. Finally, potential confounders or effect modifiers (ethnicity, sexual orientation and socioeconomic status) could not be included in the analyses.

This study revealed many opportunities for HIV indicator condition-guided testing in primary care. At this stage, however, HIV indicator conditions are not exploited as triggers for early HIV testing. According to the UK guideline, insight in a country's high-prevalence areas is a prerequisite for developing 'routine HIV testing' strategies. To move from policy to practice, there is an urgent need to identify the barriers and facilitators that affect effective implementation by GPs. 


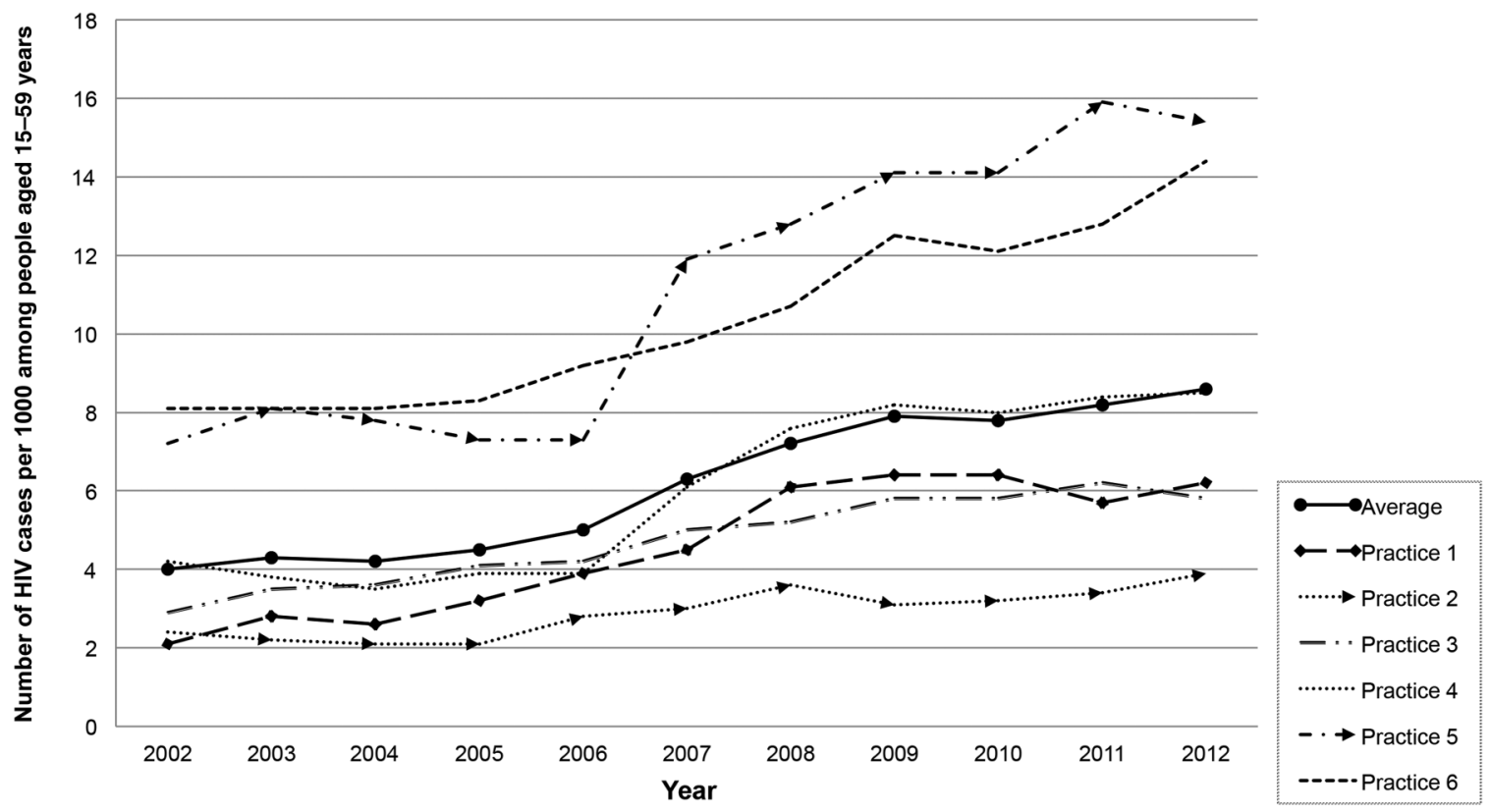

Figure 1 Trends in prevalence of HIV in six general practices in a South-Eastern district of Amsterdam, the Netherlands, $2002-2012$.

\section{Key messages}

In the year prior to diagnosis, the majority of cases in our cohort (61.8\%) visited their general practitioner at least once.

- In the 5 years prior to diagnosis, more than half $(58.8 \%)$ of all HIV cases presented with one or more HIV indicator conditions.

- This study revealed many missed opportunities for HIV indicator condition-guided testing in primary care.

\section{Handling editor Jackie A Cassell}

Correction notice This article has been corrected since it was published Online First. The first author's first name has been added.

Acknowledgements We would like to thank the GPs involved in the Network of General Practitioners of the Academic Medical Center, University of Amsterdam (HAG-net-AMC). We would also like to thank Dr J. van Es for helpful advice on data collection at the start of this project.

Contributors IKJ and DLA wrote the manuscript and performed the statistical analyses. All authors contributed to the design and/or interpretation, provided feedback and approved the final submitted version of the manuscript.

Funding This work was supported by a grant (reference: 2012074) of the Aids Fonds, Amsterdam, the Netherlands.

Competing interests None declared.

Ethics approval According to the Medical Research (Human Subjects) Act (WMO), formal approval for this research project by a medical ethics committee was not required. The academic GP network extracts data according to strict guidelines for the privacy protection of patients and GPs. In addition, we sought and obtained permission for this work from the board of the network.

Provenance and peer review Not commissioned; externally peer reviewed.

\section{REFERENCES}

1 Van Sighem Al, Gras LA, Smith CJ, et al. Monitoring Report 2014: Human Immunodeficiency Virus (HIV) Infection in the Netherlands. Stichting HIV Monitoring, 2014.

2 Van Sighem Al, Gras LA, Reiss P, et al. Life expectancy of recently diagnosed asymptomatic HIV-infected patients approaches that of uninfected individuals. AIDS 2010;24:1527-35.
3 Rodger AJ, Lodwick R, Schechter M, et al. Mortality in well controlled HIV in the continuous antiretroviral therapy arms of the SMART and ESPRIT trials compared with the general population. AIDS 2013;27:973-9.

4 Cohen MS, Chen YQ, McCauley M, et al. Prevention of HIV-1 infection with early antiretroviral therapy. N Engl J Med 2011;365:493-505.

5 Van Bergen JE. Normalizing HIV testing in primary care. Commentary on: Late HIV diagnoses in Europe: a call for increased testing and awareness among general practitioners. Eur J Gen Pract 2012;18:133-5.

6 Kall MM, Smith RD, Delpech VC. Late HIV diagnosis in Europe: a call for increased testing and awareness among general practitioners. Eur J Gen Pract 2012;18:181-6

7 Trienekens SC, van den Broek IV, Donker GA, et al. Consultations for sexually transmitted infections in the general practice in the Netherlands: an opportunity to improve STI/HIV testing. BMJ Open 2013;3:e003687.

8 Donker G, Dorsman S, Spreeuwenberg P, et al. Twenty-two years of HIV-related consultations in Dutch general practice: a dynamic cohort study. BMJ Open 2013;3:e001834.

9 Van den Broek IV, Verheij RA, van Dijk CE, et al. Trends in sexually transmitted infections in the Netherlands, combining surveillance data from general practices and sexually transmitted infection centers. BMC Fam Pract 2010;11:39.

10 Gokengin D, Geretti AM, Begovac J, et al. 2014 European Guideline on HIV testing Int J STD AIDS 2014;25:695-704.

11 Van Bergen J, Dekker J, Boeke A, et al. Dutch College of General Practitioners' guideline STD consultation (first revision) [NHG standaard: Het soa-consult (eerste herziening)]. Huisarts Wet 2013;56:450-63.

12 National Institute for Health and Care Excellence (NICE). Increasing the uptake of HIV testing to reduce undiagnosed infection and prevent transmission among men who have sex with men. Public Health Guidance 34, 2011. https://www.nice.org. uk/guidance/ph34 (accessed May 2015).

13 National Institute for Health and Care Excellence (NICE). Increasing the uptake of HIV testing to reduce undiagnosed infection and prevent transmission among black African communities living in England. Public Health Guidance 33, 2011. https://www.nice.org.uk/guidance/ph33 (accessed May 2015).

14 HIV in Europe. HIV Indicator Conditions: Guidance for implementing HIV testing in Adults in Health Care Settings, 2012. http://hiveurope.eu/Portals/0/Guidance.pdf.pdf (accessed May 2015).

15 Glew S, Pollard A, Hughes L, et al. Public attitudes towards opt-out testing for HIV in primary care: a qualitative study. Br J Gen Pract 2014;64:e60-6.

16 Boesten J, Braaksma L, Klapwijk-Strumpler S, et al. Adequate record keeping in electronic patient records [Adequate dossiervorming met het Elektronisch Patiëntendossier]. Dutch College of General Practitioners [Nederlands Huisartsgenootschap], 2013. https://www.nhg.org/sites/default/files/content/nhg_ org/uploads/richtlijn_adequate_dossiervorming_met_het_elektronisch_ patientendossier_1.pdf (accessed May 2015).

17 Sankatsing SUC, Steingrover R, Brinkman K. Acute HIV infection [Acute hiv-infectie] Tijdschr Infect 2008;3:47-52. 


\section{Clinical}

18 Burns FM, Johnson AM, Nazroo J, et al. Missed opportunities for earlier HIV diagnosis within primary and secondary healthcare settings in the UK. AIDS 2008;22:115-22.

19 Champenois K, Cousien A, Cuzin L, et al. Missed opportunities for HIV testing in newly-HIV-diagnosed patients, a cross sectional study. BMC Infect Dis 2013;13:200.

20 Scognamiglio P, Chiaradia G, De Carli G, et al. The potential impact of routine testing of individuals with HIV indicator diseases in order to prevent late HIV diagnosis. BMC Infect Dis 2013;13:473.

21 Damery $S$, Nichols $L$, Holder $R$, et al. Assessing the predictive value of HIV indicator conditions in general practice: a case-control study using the THIN database. $\mathrm{Br} J$ Gen Pract 2013;63:e370-7.

22 O+S Amsterdam. Amsterdam in numbers [Amsterdam in cijfers, Jaarboek 2014 is een productie van $0+S$ in opdracht van de Gemeente Amsterdam], 2014. http:// www.os.amsterdam.nl/assets/pdfs/2014\%20jaarboek\%20amsterdam\%20in\% 20cijfers.pdf (accessed May 2015).

23 Agusti C, Fernandez-Lopez L, Mascort J, et al. Attitudes to rapid HIV testing among Spanish General Practitioners. HIV Med 2013;14:53-6.

24 Sullivan AK, Raben D, Reekie J, et al. Feasibility and effectiveness of indicator condition-guided testing for HIV: results from HIDES I (HIV indicator Diseases across Europe study). PloS ONE 2013;8:e52845.

25 Jones A, Cremin I, Abdullah F, et al. Transformation of HIV from pandemic to low-endemic levels: a public health approach to combination prevention. Lancet 2014;384:272-9.

26 Elmahdi R, Gerver SM, Gomez Guillen G, et al. Low levels of HIV test coverage in clinical settings in the U.K.: a systematic review of adherence to 2008 guidelines. Sex Transm Infect 2014;90:119-24.

27 Hartney T, Kennedy I, Crook P, et al. Expanded HIV testing in high-prevalence areas in England: results of a 2012 audit of sexual health commissioners. HIV Med 2014;15:251-4. 